\title{
Do outro lado do silêncio: fotografias e vídeos sobre o cotidiano hiperconectado
}

\author{
Carlos Alberto Donaduzzi
}

\section{Resumo}

Este trabalho expõe um estudo crítico em torno de um ensaio visual composto por fotografias e vídeos que pretendem apresentar um pensamento sobre as relações das pessoas de hoje com a tecnologia e as redes sociais. Partindo de referências de pinturas de Edward Hopper, as imagens dessa série buscam trazer aos olhos e dar visão ao vazio e ao silêncio da vida contemporânea através de encenações com personagens envoltos em atmosferas coabitadas pelo real e o virtual.

Palavras-chave: Fotografia; silêncio; redes sociais; hiperconectividade;

\section{On the other side of silence: photographs and videos about the hyperconnected} world

\begin{abstract}
This paper exposes a critical study around a photography/video visual essay. These images intend to present a thought about the relations of today's people with technology and social media. This series presents a view of daily life based on visual references of Edward Hopper's painting. The characters in the scenes are involved in atmospheres cohabited by the real and the virtual and the images purpose a discussion about the emptiness and silence of contemporary life.
\end{abstract}

Keywords: Photography; silence; social media; hyperconnectivity;

“... o excesso de fala hoje nos convida a pensar o seu contrário - o silêncio como uma forma de sobrevivência da experiência.” (NOVAES, 2014, p. 15)

Silêncio é uma daquelas palavras que parecem absorver na escrita o seu significado de maneira eficaz. Seu som ao pronunciar reflete o seu efeito. O silêncio grita a partir da sua sílaba tônica e cala suavemente como uma brisa leve que se desfaz no ar. Silêncio, 
silêncio, silêncio! Não parece estranho repetir tantas vezes uma mesma palavra e sentir o seu significado se dissolver? Sua fala cansa, exige uma tomada de ar e uma forte expiração ao final. Requisitá-lo é senti-lo, mesmo que por segundos. O silêncio é como uma imagem indefinida, borrada e tremida, uma imagem não compreensível na sua totalidade e indecifrável na sua origem. O silêncio nem sempre parece existir (BARTHES, 2013), exige ser conquistado e encontrado por meio de camadas de ruídos.

O silêncio pode ser sentido através da respiração (ORLANDI, 2011), no pequeno intervalo entre a inspiração e a expiração, no momento mínimo onde os pulmões não estão nem cheios e nem vazios, no movimento cíclico que mantém o corpo vivo. Nesses segundos onde o tempo parece suspenso é quando o silêncio permite ouvir. Ouvi-lo e ouvir o mundo. O silêncio torna aparente as significações do que pode ser absorvido pelos sentidos (WOLFF, 2014). É como o vento que provoca o ruído das folhas e galhos das arvores que vibram em um dia de ventania, ele não é visível, mas é sentido quando em contato com a pele.

A noção de silêncio em relação à essa pesquisa em desenvolvimento surge através de um processo de percepção que descobre no decorrer do trabalho motivações que inicialmente pareciam escondidas sob camadas de outros pensamentos. Essa (re) descoberta ativa um conjunto de observações sobre o trabalho proposto que por sua vez revela inúmeras conexões entre todos os assuntos que o compõe. Nesse sentido, essa escrita que surge com a ideia de silêncio como norte e absorvido nas camadas da discussão, constitui-se a partir de uma investigação poética produzida no contexto da arte contemporânea, abordando diálogos entre a fotografia e o cinema, assim como citações a pintura e a elementos inerentes a história da arte.

Assim, constrói-se uma série de motivos que postulam como originários para essa discussão que se inicia. A visão que percebe na produção de Edward Hopper elementos que propiciam a construção de imagens pensando em um diálogo relativo a contaminações entre linguagens. A noção de proximidade com o cinema, a abordagem sobre o indivíduo e sua intimidade, e sobretudo, a observação do silêncio como fator que atravessa aspectos do cotidiano desde as representações de Hopper e que atualmente, 
mesmo que reconfigurados, ainda emitem sinais semelhantes sobre o comportamento da sociedade.

Interesso-me, além das contaminações que podem se originar do contágio entre essas linguagens, pelas narrativas que consequentemente podem surgir através de citações literais e metafóricas envolvendo ficção e realidade. Com o olhar em torno do cotidiano e dos conflitos que podem surgir da relação entre mundo natural e virtual, busco criar em cada imagem, seja em formato fotográfico ou nos vídeos que integram a série "Do outro lado do silêncio", uma expectativa por um desfecho, e a possibilidade de descoberta de algo por parte do espectador, através da percepção de uma integração entre observação do mundo e fatos ficcionais.

A velocidade, o ruído, as distrações e os excessos que preenchem cada minuto e fazem com que parte da sociedade se mantenha conectada, ocupada e incapaz de perceber seu entorno influenciou na construção dessas fotografias e vídeos. Essa atmosfera de excessos que transbordam a vivência cotidiana passou a tornar-se mais constantes em minhas observações e em fotografias que realizava nas ruas e demais espaços com aglomerações de pessoas. Nessa aparente reconfiguração do comportamento, a solidão e o silêncio parecem ter se transformados em inimigos a serem evitados ao ponto de abdicarmos da própria liberdade na ânsia de sermos notados (KAGGE, 2016). Vivemos em um mundo bombardeado de informações, repleto de ruídos sonoros e visuais, lutamos contra o tédio e buscamos a cada segundo mantermo-nos ocupados, muitas vezes em busca de alegrias efêmeras que preencham qualquer possibilidade de confronto consigo mesmo.

As cenas retratadas na série "Do outro lado do silêncio" possuem origem na interpretação da ideia de silêncio como elemento de exceção diante de uma atmosfera de ruído. Baseadas inicialmente em pinturas do artista estadunidense Edward Hopper, as imagens pretendem evidenciar momentos de interação, das pessoas com os aparelhos tecnológicos, e principalmente, as reações diante das interfaces sociais, visando construir retratos sobre diferentes intimidades. As fotografias e vídeos dessa série são uma interpretação da densidade dramática e conceitual das interações cotidianas que Hopper também retratou, agora atualizadas e percebidas através da observação do mundo atual. 


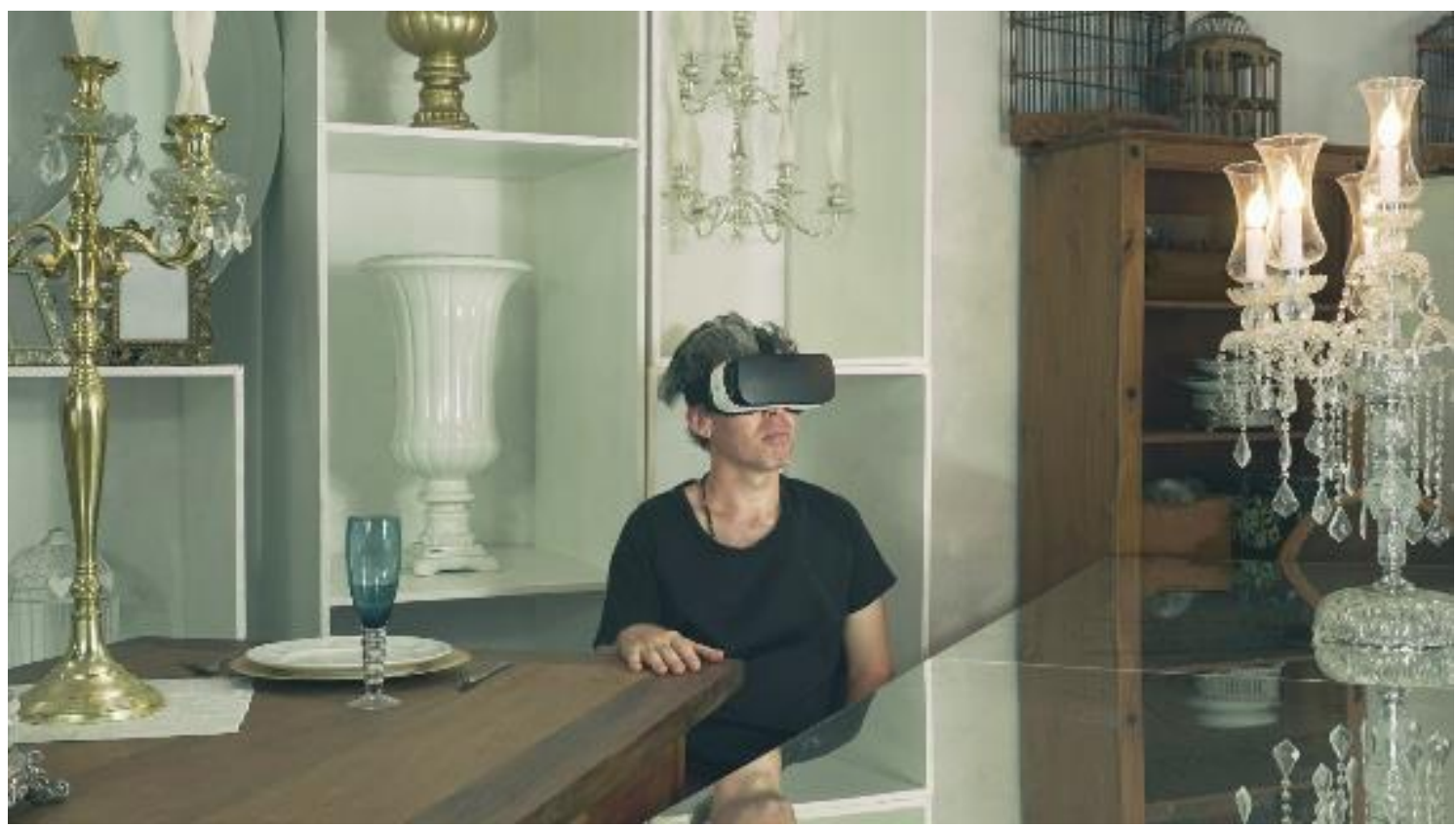

Fig. 1. Carlos Donaduzzi, Já não consigo mais viver nesse mundo, 2018. Fotografia, 125 x $70 \mathrm{~cm}$.

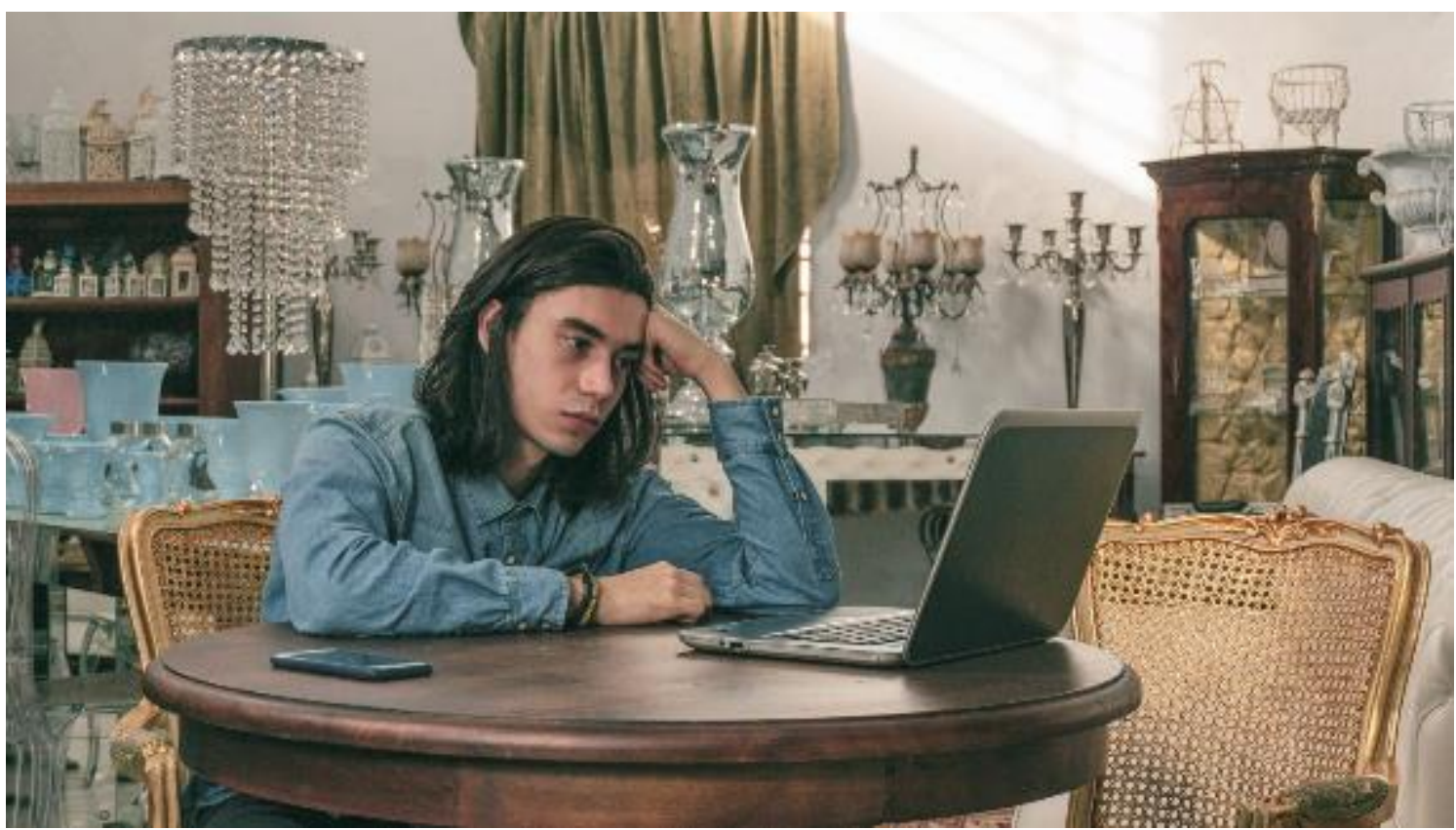

Fig. 2. Carlos Donaduzzi, Vazio acumulado, 2018. Fotografia, 125 x $70 \mathrm{~cm}$. 


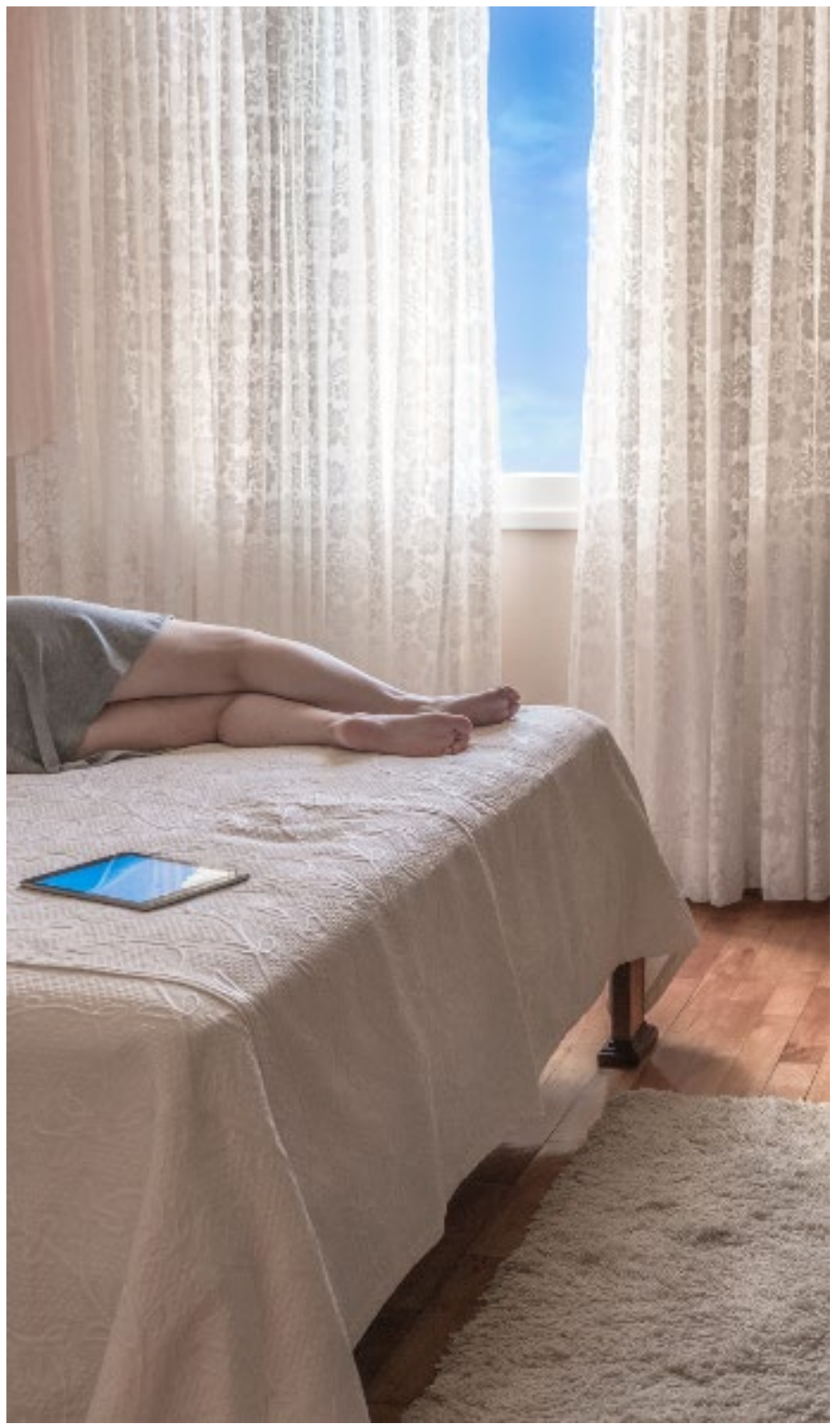

Fig. 3. Carlos Donaduzzi, O espelho, 2018. Fotografia, 125 x $70 \mathrm{~cm}$.

De uma maneira geral, as imagens aqui apresentadas se dedicam, em um primeiro olhar, interpretar e propor a ideia de distanciamento e incomunicabilidade. A circular por esses diferentes mundos de realidades distintas, entre o físico e o virtual, o interior e exterior dos aparelhos eletrônicos e as conexões em rede, o indivíduo extrapola formas de vivências e sensações. "Já não consigo mais viver nesse mundo" (fig.1), é uma fotografia que pretende discutir sobre essas possibilidades de realidades e seus possíveis distanciamentos. Mergulhado em uma experiência individual de imersão em realidade 
virtual, o personagem, a não ser por sua mão direita que tenta manter um vínculo de contato com a realidade física, não parece se comportar de maneira natural no espaço em que se encontra inserido.

Já em "Vazio acumulado" (fig.2), a mesa com duas cadeiras e a possibilidade de diálogo é substituída por uma presença virtual representada pelo computador e o celular, companhias do personagem que parece aguardar há um longo período de tempo uma resposta ou um sinal. O silêncio e a busca por transpor o tédio do personagem é oriundo da interpretação da obra "Quarto em Nova Iorque", óleo sobre tela de 1932, de Edward Hopper. Na pintura, dois personagens dividem o mesmo ambiente, próximos e ao mesmo tempo afastados por um abismo que tem o elemento da mesa como símbolo de uma barreira comunicacional e ao mesmo tempo de um convívio despedaçado.

Sobre esse mesmo aspecto de intimidade compartilhada, na pintura 1959, "Excursão filosófica”, Hopper constrói uma cena com elementos mínimos, mas potentes. A mulher seminua adormecida tem seu rosto anônimo diante de um homem vestido e sentado à beira da cama com um olhar vazio e aparentemente hipnotizado por um ponto invisível ao chão. A possibilidade de imaginar uma nova cena influenciou o processo de criação de "O espelho" (fig.3), fotografia que pretende dialogar com a pintura em questão.

Através de outro ângulo, da construção de outro cenário, a mulher solitária e também anônima habita um quarto onde a luz intensa e geométrica é substituída por uma luminosidade suave e esmaecida. A presença do outro personagem existente no quadro de Hopper é agora uma marca na cama, de alguém que não está mais naquele espaço e o livro aberto se converte em um aparelho eletrônico com uma imagem que reflete a luz do céu. Nesse sentido, busca-se provocar os limites de compreensão da realidade, um céu idealizado, tanto na janela quanto na tela do equipamento eletrônico, elementos de hesitação que aspiram questionar o caráter ficcional do cotidiano que é difundido nas redes sociais.

Durante o desenvolvimento da série "Do outro lado do silêncio" percebi que em algumas das imagens era possível extrapolar a condição fixa da imagem fotográfica e assim assumir os movimentos que as mesmas indicavam em suas composições. Mesmo assim, os vídeos que surgiram dessa experimentação não pretendem apresentar um 
possível desfecho para as suposições de enredo, mas sim potencializar pela repetição a espera por um futuro que possa existir e que a imagem venha a indicar. "Entardecer das escolhas" (fig.4), é a tentativa que inaugura a busca por uma imagem que represente o limite que separa a fotografia do vídeo. Sua imagem é simultaneamente fixa e móvel, um instante contínuo.

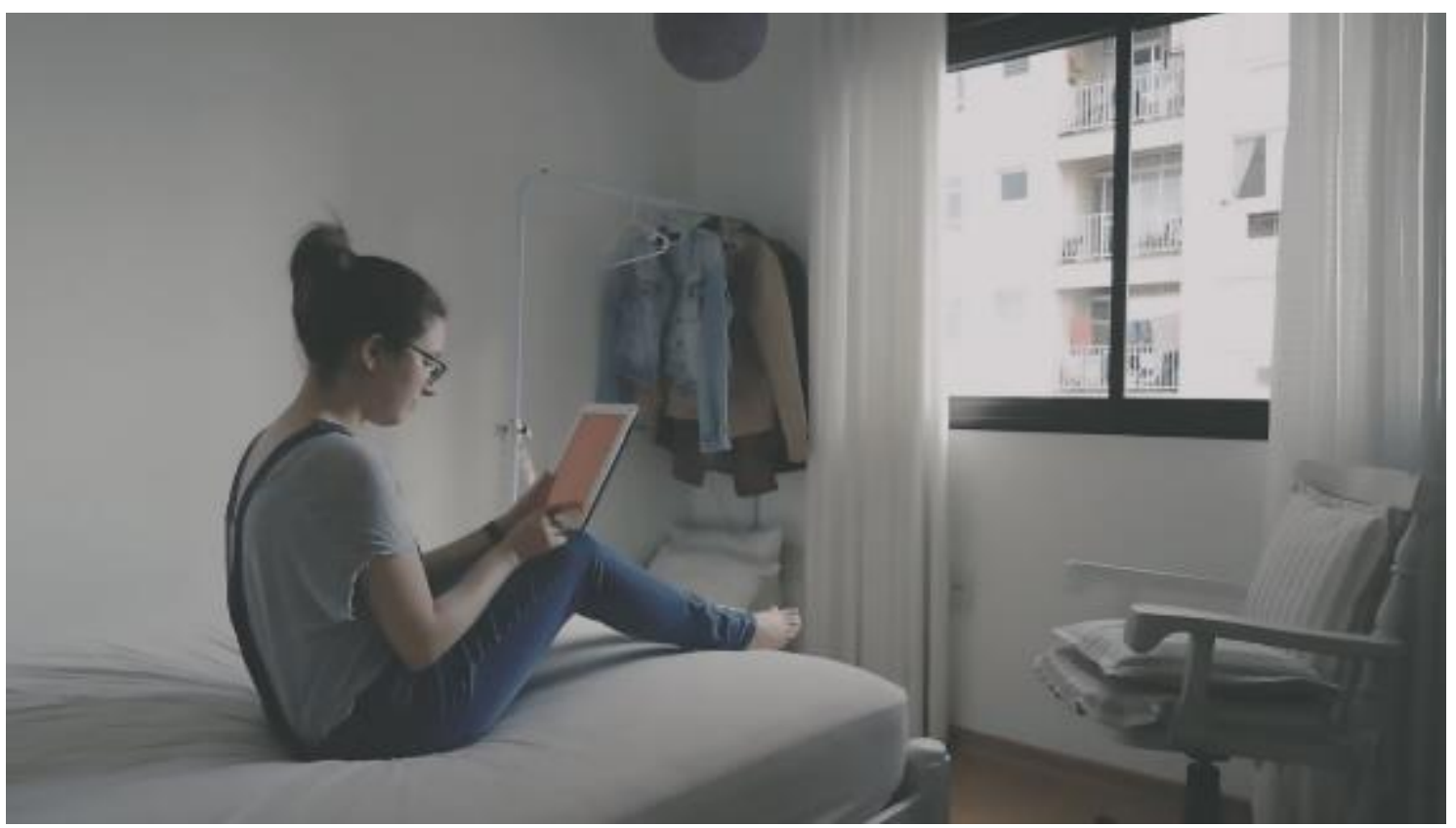

Fig. 4. Carlos Donaduzzi, Entardecer das escolhas, 2017. Vídeo, 1:35min (Loop), 38x30,5cm. (disponível em https://vimeo.com/262852991) 


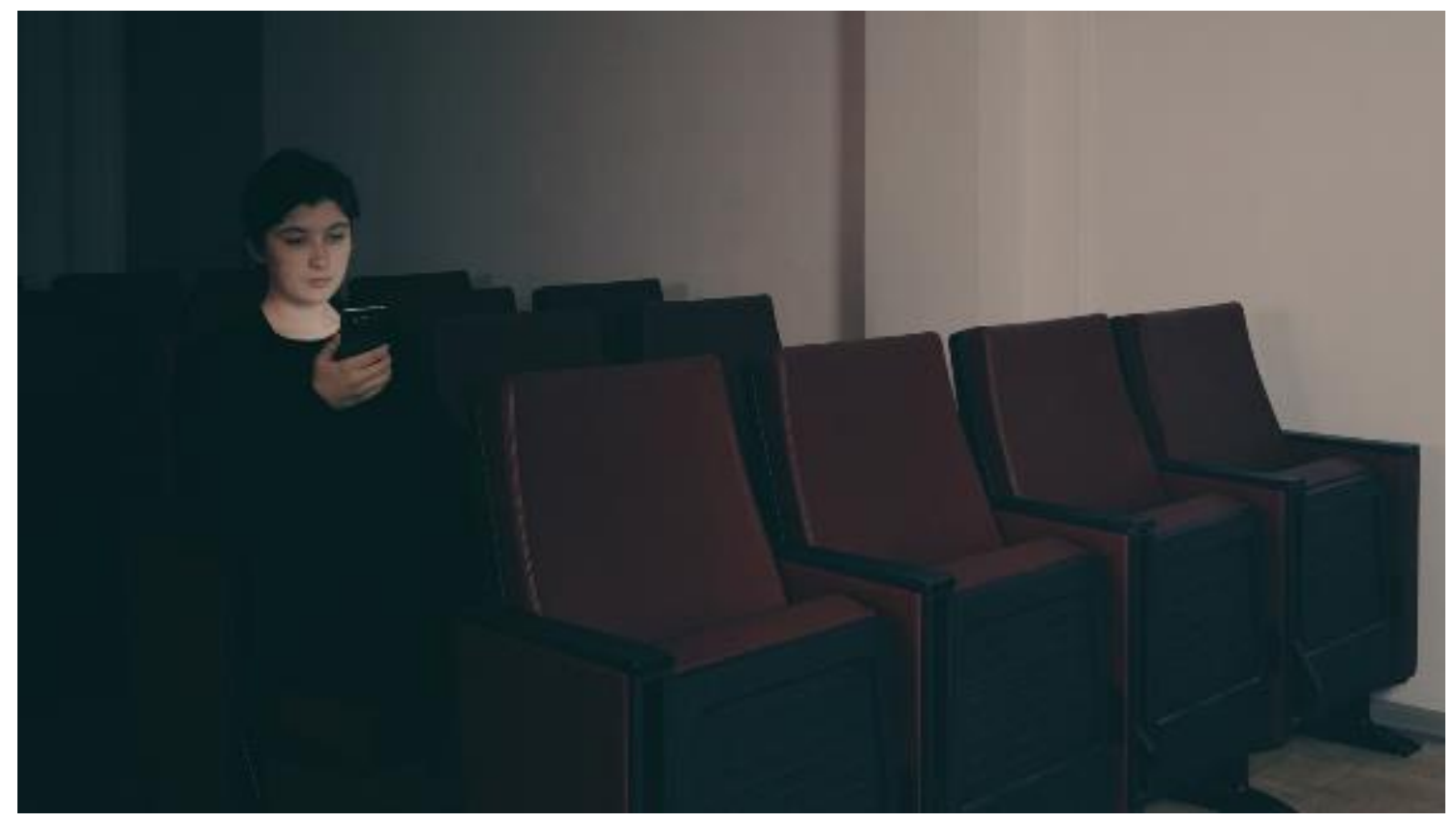

Fig. 5. Carlos Donaduzzi, Sessão de um filme sem nome, 2017. Vídeo, 1:09min (Loop), 38x30,5cm. (disponível em https://vimeo.com/262864652)

Do mesmo modo acontece em "Sessão de um filme sem nome" (fig.5), um vídeo em constante repetição sobre uma personagem solitária em uma sala de cinema. Assim como em "Intervalo", 1963, de Edward Hopper, a personagem solitária em uma sala de cinema também não tem sua atenção direcionado para a projeção do filme. Desse modo, o olhar é resinificado e agora ocupa uma pequena tela que em intervalos indeterminados de tempo ilumina e aprisiona a atenção da personagem do vídeo para algo externo ao momento e ao espaço ocupado.

Nesses dois vídeos não há vestígios de ruídos, não há trilha sonora e não há fỉm para o que a cena mostra. Os olhares não mudam de direção, os personagens estão anestesiados pela repetição, aprisionados nesse tempo cíclico e sobretudo alienados devido ao brilho que emana dos aparelhos eletrônicos que suplicam a sua atenção. Essa condição de espera por algo refletiu na maneira de expor o próprio trabalho. Emoldurado, a tela que exibe o vídeo (fig.6) propõe uma relação de intimidade que se pretende extrair entre obra e espectador. Sentado diante de uma tela, busca-se propor uma pausa, um olhar contemplativo e sobretudo refazer uma noção de "tempo perdido" diante de uma obra que não trará desfecho para o seu conflito, apensar de supostamente indicar isso. Trata-se de 
uma tentativa de passar para o espectador a sensação das personagens que habitam esses vídeos.

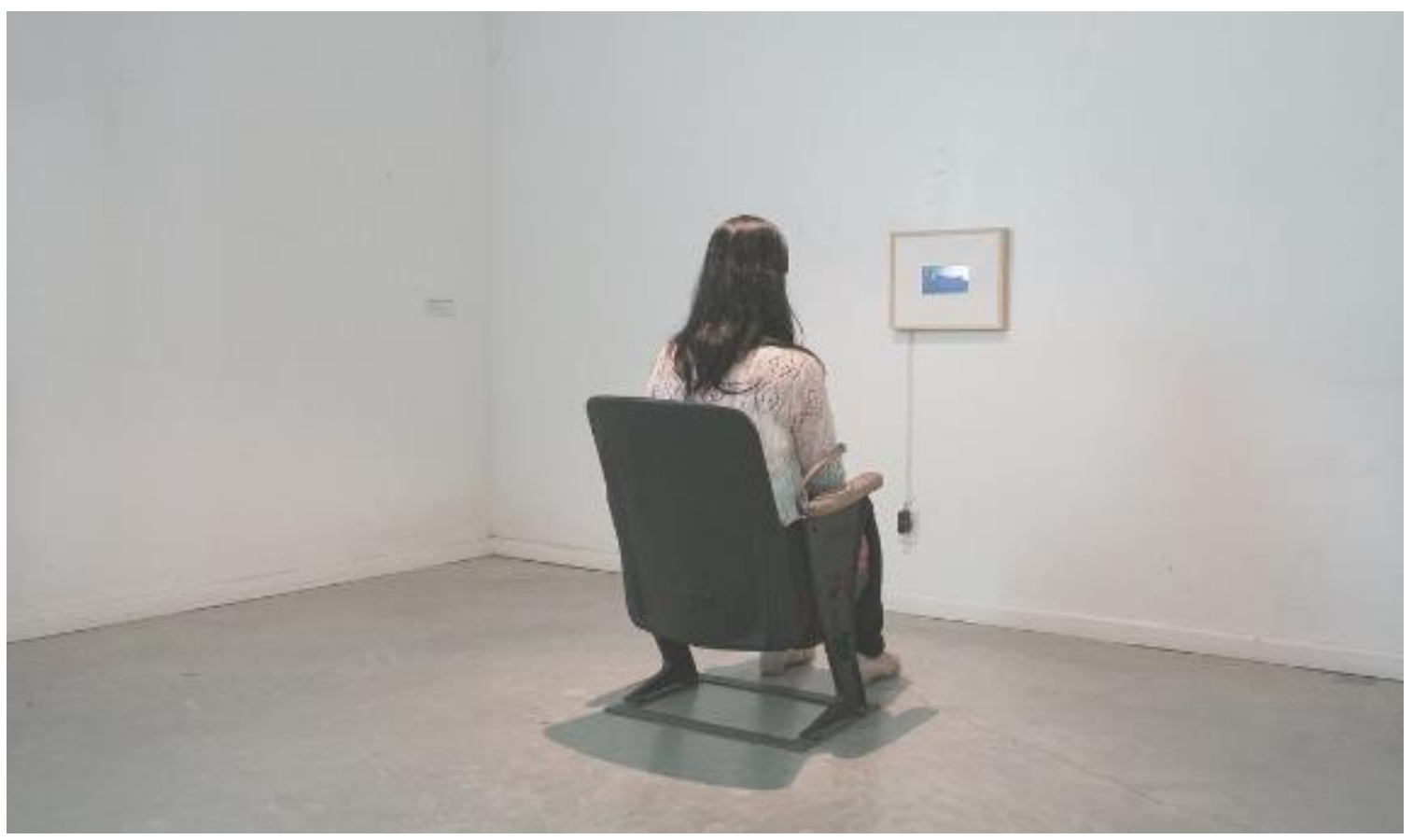

Figura 6 - Suporte de exibição dos vídeos em ambiente expositivo. Exposição "Arte, cinema e Audiovisual”, Sala Cláudio Carriconde, Santa Maria - RS, 2018.

E, sobre estar só e acompanhado, ainda que através de presenças virtuais acessadas pelo smartphone que este ensaio é finalizado com a fotografia "Uma e muitas pessoas" (fig.7), novamente uma imagem fixa, reforçando a noção de solidão e silêncio que permeia todo trabalho. Referência direta a pintura "Pessoas ao sol", óleo sobre tela de 1960 de Edward Hopper, a fotografia revela um espaço de acúmulos e inutilidades, onde uma luz corta diagonalmente a cena, iluminando não só os objetos, mas também a face dessa pessoa que mantém o seu olhar para a pequena tela que o transporta para outro lugar. Sob essa última imagem pretende-se sintetizar um pensamento que se fez presente durante o processo de produção das obras, a construção de atmosferas densas, repletas de sentimentos e conflitos pessoais que se manifestam no cotidiano. 


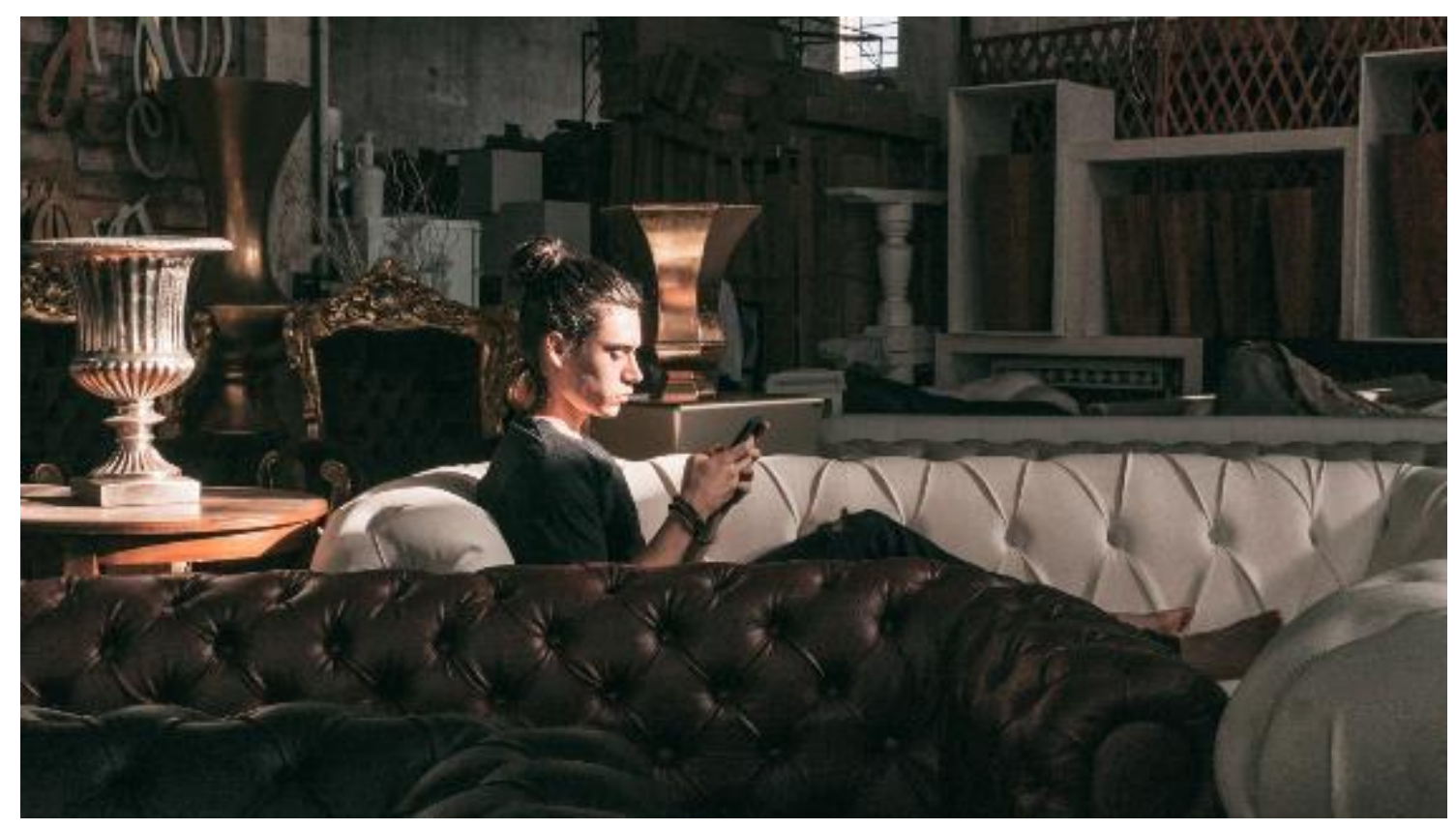

Fig. 7. Carlos Donaduzzi, Uma e muitas pessoas, 2018. Fotografia, 177 x $100 \mathrm{~cm}$.

De caráteres distintos e destacando diálogos entre a pintura, a fotografia e o cinema, busca-se com esses trabalhos um pensamento sobre a hiperconectividade e a vida dupla, entre o real e o virtual e como essa condição impacta nas relações e interações entre as pessoas na contemporaneidade. "Do outro lado do silêncio" é uma interpretação sobre os olhares em direção as telas luminosas e a espera por respostas, por um chamado, um segundo de atenção ou qualquer outra coisa que permita fugir da realidade a céu aberto (DUNKER, 2017, p. 22). É também sobre buscar e receber pequenas doses de alegria, tão efềmeras que logo serão necessárias novamente. É sobre não perceber o seu entorno e é sobre olhar-se em um espelho negro e não se identificar com o seu reflexo.

\section{Referências}

BARTHES, Roland. O Neutro. São Paulo: Martins Fontes, 2013.

DUNKER, Christian. Reinvenção da intimidade: políticas do sofrimento cotidiano. São Paulo:

Ubu editora, 2017. 
KAGGE, Erling. Silêncio: na era do ruído. Rio de Janeiro: Editora Schwarcz S.A, 2016.

NOVAES, Adauto. Mutações: o silêncio e a prosa do mundo. São Paulo: Edições SESC, 2014.

ORLANDI, Eni. As formas do silêncio: no movimento dos sentidos. 2 ed. Campinas, SP:

Editora da UNICAMP, 2011.

WOLFF, Francis. O silêncio é ausência de quê? In: NOVAES, Adauto (Org.). Mutações: o silêncio e a prosa do mundo. São Paulo: Edições SESC, 2014. Cap.3, p.29-51. 